\section{Spontaneous regression of a giant pulmonary bulla}

\author{
David A Bradshaw, Kevin M Murray, \\ Dennis E Amundson
}

\begin{abstract}
Gradual expansion of a lung bulla is common and may be associated with debilitating pulmonary symptoms. The aetiology of bulla expansion is unclear. Spontaneous regression, on the other hand, is rarely observed. The case is presented of a man in whom near complete spontaneous resolution of a giant pulmonary bulla occurred. This event was associated with dramatic improvement in the radiographic picture and pulmonary function.
\end{abstract}

(Thorax 1996;51:549-550)

Keywords: emphysema, giant bulla, spontaneous regression, pulmonary function.

Pulmonary bullae occur as isolated abnormalities in otherwise normal lung tissue or, more frequently, in the setting of generalised emphysema. ${ }^{1}$ Although long periods of stability are not uncommon, the natural history of pulmonary bullae is often characterised by gradual, progressive enlargement. ${ }^{23}$ Spontaneous regression, on the other hand, is unusual. We present the case of an elderly man with severe bullous emphysema who experienced dramatic improvement in pulmonary function following spontaneous regression of a giant lung bulla.

\section{Case report}

A 70 year old man with bullous emphysema attended the pulmonary clinic for many years with symptoms of fatigue and dyspnoea on exertion. He denied frequent cough, sputum production, or wheezing. He had an 80 packyear smoking history but had stopped in 1984 .

Sequential pulmonary function tests performed during follow up period

\begin{tabular}{|c|c|c|c|c|}
\hline & $\begin{array}{l}\text { August } \\
1989\end{array}$ & $\begin{array}{l}\text { October } \\
1990\end{array}$ & $\begin{array}{l}\text { September } \\
1991\end{array}$ & $\begin{array}{l}\text { October } \\
1993\end{array}$ \\
\hline $\mathrm{FEV}_{1}(\mathrm{l} ; \%$ predicted $)$ & $1 \cdot 34(36)$ & $1 \cdot 31(38)$ & $0.72(21)$ & $2 \cdot 26(63)$ \\
\hline FVC $(1 ; \%)$ & $3.84(82)$ & $3 \cdot 18(71)$ & $1.95(44)$ & $4.37(96)$ \\
\hline $\mathrm{FEV}_{1} / \mathrm{FVC}$ & 35 & 41 & 37 & 52 \\
\hline $\mathrm{FEF}_{25-75}(1 ; \%)$ & $0.40(11)$ & $0.45(12)$ & $0 \cdot 27(7)$ & $0.89(25)$ \\
\hline $\operatorname{TLC}(1 ; \%)$ & $6 \cdot 50(92)$ & $7 \cdot 9(113)$ & $7 \cdot 83(111)$ & $8 \cdot 36(120)$ \\
\hline $\mathrm{RV}(1 ; \%)$ & $3 \cdot 30(125)$ & $4.39(166)$ & $4.79(182)$ & $3.99(148)$ \\
\hline FRC $(\mathrm{He})(1 ; \%)$ & $3.97(99)$ & $4 \cdot 17(102)$ & $4.00(94)$ & $4 \cdot 23(111)$ \\
\hline FRC (P1) $(1 ; \%)$ & & $4.88(120)$ & $5.55(131)$ & \\
\hline $\operatorname{TLCO}(\mathrm{ml} / \mathrm{min} / \mathrm{kPa} ; \%)$ & $4.09(53)$ & $4 \cdot 29(58)$ & $2.98(43)$ & $4 \cdot 59(58)$ \\
\hline
\end{tabular}

$\mathrm{FEV}_{1}=$ forced expiratory volume in one second; $\mathrm{FVC}=$ forced vital capacity; $\mathrm{FEF}_{25-75}=$ forced mid expiratory flow; TLC = total lung capacity; $\mathrm{RV}=$ residual volume; $\mathrm{FRC}(\mathrm{He})=$ forced residual capacity (helium dilution); FRC $(\mathrm{Pl})=$ forced residual capacity (plethysmography); TLCO $=$ carbon monoxide transfer factor.
Progressive deterioration in his pulmonary function coincided with the gradual enlargement of a large right lung bulla. Diffuse emphysematous changes on computed tomographic (CT) scanning and a low diffusing capacity precluded consideration of bullectomy.

On routine follow up spirometric testing in October 1993 the patient's lung function was noted to be markedly improved (table). Repeat spirometric testing verified a 1.541 increase in forced expiratory volume in one second $\left(\mathrm{FEV}_{1}\right)$. The chest radiograph showed a significant reduction in the size of the right lung bulla as well as a new $2 \mathrm{~cm}$ right lower lung nodule. Further evaluation included repeat CT scanning, bronchoscopic examination, and a lung perfusion scan. The CT scan confirmed a remarkable reduction in the size of the bulla compared with previous studies (figure). The $2 \mathrm{~cm}$ right lower lobe solitary nodule was not associated with mediastinal adenopathy. No endobronchial lesions were identified at bronchoscopy. The lung perfusion scan showed $52 \%$ of total flow to the right lung, significantly greater than the $20 \%$ observed in 1989 . The patient subsequently underwent resection of a benign lung nodule.

\section{Discussion}

Pulmonary "bullae" are pathologically dilated air spaces distal to the terminal bronchiole and are more than $2 \mathrm{~cm}$ in diameter in the distended state. ${ }^{4}$ By convention they are called "giant bullae" when they occupy over one half the volume of the hemithorax.

The mechanism of expansion of giant bullae is uncertain. ${ }^{5}$ The most widely held theory is that partial obstruction of the airways acts as a one way valve in an area of emphysematous lung and the resultant air trapping leads to gradual enlargement of the air space. Tension in the bulla may cause compression of neighbouring lung parenchyma, atelectasis, and even mediastinal shift. This theory was recently questioned by Morgan et $a l^{6}$ who measured the pressures in the giant bullae of four preoperative patients and found that the pressures in the bullae mirrored the pleural pressure and were not "under tension". Based on this and other observations they postulated that bullae enlarge because of the relatively greater elastic recoil of adjacent lung parenchyma. In other words, surrounding lung tissue retracts away from the pathologically dilated air space.

The natural history of pulmonary bullae is unpredictable, although gradual enlargement over time is commonly observed. ${ }^{23}$ Occasionally, rapid symptomatic expansion of bullae occurs for unknown reasons. Although spontaneous regression and even apparent radiographic resolution have been previously described, this is very uncommon. Most reported cases have been associated with infection manifested by cough, sputum production, and an air/fluid level on the radiograph..$^{7-9}$ The authors hypothesised that 

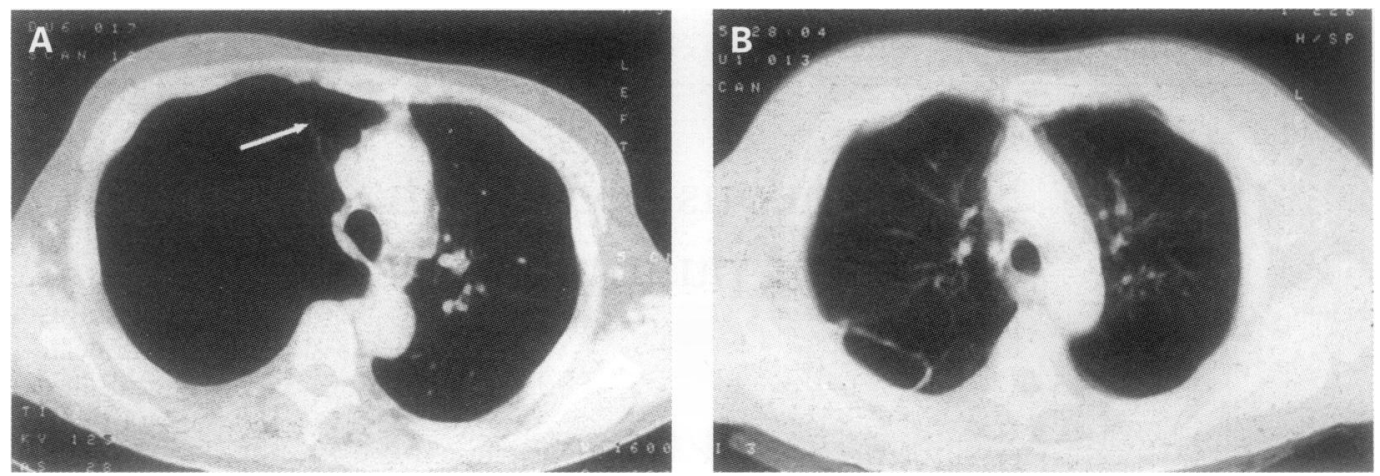

Computed tomographic scan of the chest from (A) 1991 showing a giant bulla in the right lung with significant shift of the mediastinum to the left and $(B)$ in 1993 showing a dramatic reduction in the size of the bulla. Note that the lung is almost completely re-expanded and the mediastinal shift is resolved.

inflammation may further obstruct already compromised bronchial communications with the bullae resulting in a closed space. Eventually fluid and then air resorption leads to regression of the bulla. If this mechanism is valid, one might speculate that other known causes of airway obstruction such as tumour, mucous plugging, or blood clot could also lead to shrinkage of the bulla. A retrospective review from Japan reported three cases of lung bulla regression associated with bronchogenic cancer, although no details on individual cases were provided. ${ }^{10}$

Our case is of interest not only because of the rarity with which spontaneous regression has been reported in the literature, but also because it was associated with such dramatic improvements in the radiological picture and pulmonary function. Unlike earlier reports, this occurred in the absence of overt infection or tumour. Re-expansion of compressed lung and reversal of mediastinal shift was accompanied by improved pulmonary blood flow. Substantial increases in $\mathrm{FEV}_{1}$, as documented in this patient, are sometimes seen following surgical bullectomy in well selected patients. Our patient was not thought to be a good candidate for bullectomy because of diffuse emphysema, which underlines the difficulty in selecting patients for surgery.

The Chief, Bureau of Medicine and Surgery, Navy Department, Washington, DC, Clinical Investigation Program sponsored this report \#84-16-1968-495, as required by HSETCINST $6000.41 \mathrm{~A}$. The views expressed in this article are those of the authors and do not reflect the official policy or position of the Department of the Navy, Department of Defense, or the United States Government.

1 Thurlbeck WM. Chronic airflow obstruction. In: Pathology of the lung. Stuttgart, New York: Thieme Medical Publishers, 1988:549-50.

2 Boushy SF, Kohen R, Billig DM, Heiman MJ. Bullous emphysema: clinical, roentgenologic and physiologic study of 49 patients. Dis Chest 1968;54:327-34.

3 Stone DJ, Schwartz A, Feltman JA. Bullous emphysema. A long-term study of the natural history and the effects of therapy. Am Rev Respir Dis 1960;94:493-507.

4 CIBA Guest Symposium. Terminology, definitions, and classification of chronic pulmonary emphysema and related conditions. Thorax 1959;14:286-99.

5 Murphy DM, Fishman AP. Bullous disease of the lung. In: Fishman AP, ed. Pulmonary diseases and disorders. New York: McGraw-Hill, 1988:1219-22.

6 Morgan MD, Edwards CW, Morris J, Matthews HR. Origin and behaviour of emphysematous bullae. Thorax 1989; and b33-8.

7 Rubin EH, Buchberg AS. Capricious behavior of pulmonary bullae developing fluid. Dis Chest 1968;54:546-9.

8 Rothstein E. Infected emphysematous bullae. Report of five cases. Am Rev Tuberc 1954;69:287-96.

9 Douglas AC, Grant IW. Spontaneous closure of large pulmonary bullae. A report on three cases. $B r$ Tuberc Dis Chest 1958;33:335-8.

10 Tsutsui M, Araki Y, Shirakusa T, Inutsuka S. Characteristic radiographic features of pulmonary carcinoma associated with large bulla. Ann Thorac Surg 1988;46:679-83.
Cardiothoracic

Centre,

Liverpool L14 3PE,

UK

G E Wilson

C C Evans

Correspondence to:

Dr C C Evans.

Received 9 September 1994 Returned to authors 30 November 1994 Revised version received 20 February 1995 Accepted for publication 24 February 1995

\section{Sternocostoclavicular hyperostosis presenting with thoracic sinus formation}

\author{
G E Wilson, C C Evans
}

\author{
Abstract \\ Sternocostoclavicular hyperostosis (SCCH) \\ is a condition which is well described in the \\ Japanese literature but is rare in Western \\ Europe. It is characterised by pain and
}

A 75 year old woman of Ashkenazi Jewish extraction was referred because of increasing shortness of breath. For five years she had suffered from recurrent clavicular problems. Initially this had been swelling, pain, and stiffness around the medial ends of the clavicles 